\title{
ARTE RUPESTRE PINTADO EN EL ALERO PAMPA EL MUERTO 11 DE LA PRECORDILLERA DE ARICA: PROPUESTA ESTILIISTICA Y SECUENCIA CRONOLÓGICA
}

\author{
ROCK ART PAINTINGS OF THE PAMPA EL MUERTO ROCK SHELTER 17 , \\ ARICA FOOTHILLS ZONE (NORTHERN CHILE): STYLISTIC PROPOSAL AND \\ CHRONOLOGICAL SEQUENCE
}

Zaray Guerrero*a \& Marcela Sepúlveda ${ }^{B}$

El arte rupestre de la precordillera de Arica (2500-3800 msnm) ha sido abordado generalmente desde aproximaciones descriptivas a escala macro o regional, omitiendo las particularidades que presentan las diferentes localidades arqueológicas que la componen. En este sentido, se propone el estudio estilístico de una de las principales concentraciones de pinturas de la región, Pampa El Muerto (altura promedio $3100 \mathrm{msnm}$ ), a partir del análisis del alero Pampa El Muerto 11, el cual presenta una evidente heterogeneidad estilística y múltiples superposiciones.

Palabras clave: arte rupestre, escala de análisis, estilo, cronología, contexto arqueológico, norte de Chile.

Rock art in the precordillera (2500-3800 masl) of Chile's far north has generally been described at the macro or regional scale, omitting the particularities of the individual archaeological localities in which it is found. This paper presents the findings of a stylistic study of one of the region's foremost rock painting sectors, Pampa El Muerto (3100 masl on average), focusing on Pampa El Muerto 11, which displays evident stylistic heterogeneity and multiple superimposed images.

Keywords: rock art, scale of analysis, style, chronology, archaeological context, Northern Chile.

\section{INTRODUCCIÓN}

Una aproximación arqueológica del arte implica considerar las representaciones rupestres como una materialidad significativa para comprender procesos socio-culturales, así como prácticas económicas e ideológicas de las sociedades pasadas. De ahí que su interpretación y función incorpore información de los contextos humanos asociados, en cuanto a tipo de actividades realizadas, temporalidad e intensidad y posibles variaciones en el tiempo. Asimismo, supone un análisis exhaustivo de las imágenes, de forma que contribuyan recíprocamente a la lectura de los contextos correspondientes. Esta mirada se ha impuesto en los últimos años en los estudios de arte rupestre en Chile y Argentina, de modo que, a las aproximaciones previas, esencialmente descriptivas, se han sumado enfoques tecnológicos (Fiore 2007; Valenzuela 2007, 2013; Sepúlveda 2011b; Vergara 2013), económicos e ideológicos (Ballester \& Gallardo. 2016; Berenguer 2004a y 2004b; Dudognon \& Sepúlveda 2016; Gallardo 2001, 2009; Gallardo et al 2006; Troncoso et al. 2016; Sepúlveda et al. 2017; Vilches \& Cabello 2011; entre otros), que integran la información contextual asociada para su interpretación.

\footnotetext{
A Zaray Guerrero, Programa de Doctorado en Antropología UTA-UCN, Arica, Chile, E-mail: zguerrerobueno@gmail.com

B Marcela Sepúlveda, Instituto de Alta Investigación (IAI), Laboratorio de Análisis e Investigaciones Arqueométricas (LAIA), Universidad de Tarapacá, Arica, Chile-umR 8096 ArchAm (cNRs-París 1), París, Francia, E-mail: marcelaasre@gmail.com
} 
En la última década, diversas investigaciones en la precordillera de Arica del extremo norte de Chile, en particular en las cuencas altas de los valles de Lluta y Azapa, han permitido evidenciar una de las mayores concentraciones de arte rupestre del desierto de Atacama, con 105 sitios reconocidos/documentados hasta ahora (Sepúlveda et al. 2010, 2013, 2017; Dudognon \& Sepúlveda 2016; Meier et al. 2016). En la cuenca alta del valle de Azapa, en torno al río Tignamar, se ha registrado un significativo número de aleros con representaciones en distintas localidades, tales como Pampa El Muerto, Tangani, Mullipungo y Pampa Oxaya (Meier et al. 2016; Sepúlveda et al. 2010, 2013, 2017), completando estudios previos realizados desde la década de 1960 (Niemeyer 1972, Santoro \& Dauelsberg 1985, Schiappacasse \& Niemeyer 1996, Muñoz \& Briones 1996).

En la precordillera, el arte rupestre ha sido abordado desde dos enfoques distintos, aunque complementarios: a nivel de región, para la definición de grupos estilísticos, rescatando una mayor heterogeneidad gráfica y composicional del "estilo Sierra de Arica" (Niemeyer 1972; Sepúlveda 2008, 2011a; Sepúlveda et al. 2013); y a nivel de panel, para el estudio de la temática y las composiciones escénicas (Santoro \& Dauelsberg 1985; Dudognon \& Sepúlveda 2013, 2018). En todos estos casos, los contextos arqueológicos asociados han sido empleados para asignar una cronología relativa a los diferentes motivos, escenas y grupos estilísticos identificados, siendo adscritos consecuentemente a distintas fases de la secuencia ocupacional regional. En síntesis, el arte rupestre precordillerano ha sido atribuido, por un lado, a cazadores-recolectores arcaicos (Santoro \& Dauelsberg 1985, Muñoz \& Briones 1996) y su continuidad en el Formativo (Schiappacasse \& Niemeyer 1996; Sepúlveda et al. 2013, 2017), y por otro, a grupos agroalfareros y aldeanos o caravaneros de los períodos Intermedio Tardío y Tardío incaico (siglos XI-XVI) (Niemeyer 1972, Mostny \& Niemeyer 1983, Muñoz \& Briones 1996).

Sumada a la diversidad estilística ya enunciada mediante la definición de dos grupos (GE-1 y GE-2) de la tradición naturalista (Sepúlveda et al. 2013, 2017), pensamos que la variabilidad cronológica asociada a los sitios de arte rupestre puede reflejar la existencia de una mayor heterogeneidad tipológica, temática y escénica que pudo evolucionar en el tiempo, así como entre las distintas localidades de la precordillera (Sepúlveda \& Guerrero 2014). La tradición naturalista, relacionada con grupos cazadores-recolectores arcaicos y formativos de la zona (Sepúlveda et al. 2017), engloba solo una parte de las representaciones pintadas en este piso, ya que se evidencian otras manifestaciones figurativas y geométricas en los paneles (Muñoz \& Briones 1996, Sepúlveda 2008, Guerrero 2016, Meier et al. 2016), que podrían vincularse con otros períodos de la secuencia cronológica regional; no obstante, sus características estilísticas no han sido precisadas.

Desde este escenario, enfatizamos la necesidad de aproximaciones a distintas escalas, desde micro a macro, y viceversa (Butzer 1982), que consideren, además, diferentes niveles de análisis (motivo, panel y sitio) para precisar la variación y distribución de los patrones de representación en y entre diferentes paneles, al interior del sitio y en una localidad arqueológica, por evidenciarse trayectorias locales e historias particulares en los distintos espacios precordilleranos identificados (Saintenoy et al. 2017, Sepúlveda et al. 2018).

Para avanzar en la definición de las escalas de análisis y abordar uniformemente el arte rupestre en las tierras altas del extremo norte de Chile, nos centramos en el estudio del sector Pampa El Muerto, el cual consideramos relevante debido a que presenta: 1) una de las principales concentraciones de pinturas rupestres en aleros en la región: 19 sitios; 2) información contextual precisa y variada obtenida a partir de prospecciones intensivas en el área y de la excavación de diversos depósitos arqueológicos asociados a los sitios de arte rupestre; 3) una extensa secuencia de ocupación representativa de las distintas fases y períodos arqueológicos definidos en la región; y 4) una variabilidad estilística que, unido a las superposiciones, permiten aplicar análisis a distintas escalas y obtener una óptima resolución de la práctica rupestre.

Junto con la síntesis de la información arqueológica disponible en Pampa El Muerto, consideramos el análisis del sitio Pampa El Muerto 11 (en adelante PM-11), por evidenciar, a diferencia de los demás sitios, una clara variabilidad estilística y múltiples superposiciones, escasas en la localidad. A partir de los motivos, temática, escenas y superposiciones, definimos patrones de representación y distintas fases de ejecución de las pinturas, las que son atribuidas por contigüidad a distintos momentos de la cronología regional (Gallardo 1996), pese a las limitantes que presentan los métodos de datación indirecta del arte rupestre (Pettit \& Pike 2007). Se establece así un diálogo entre contexto arqueológico y visual. Esto se 


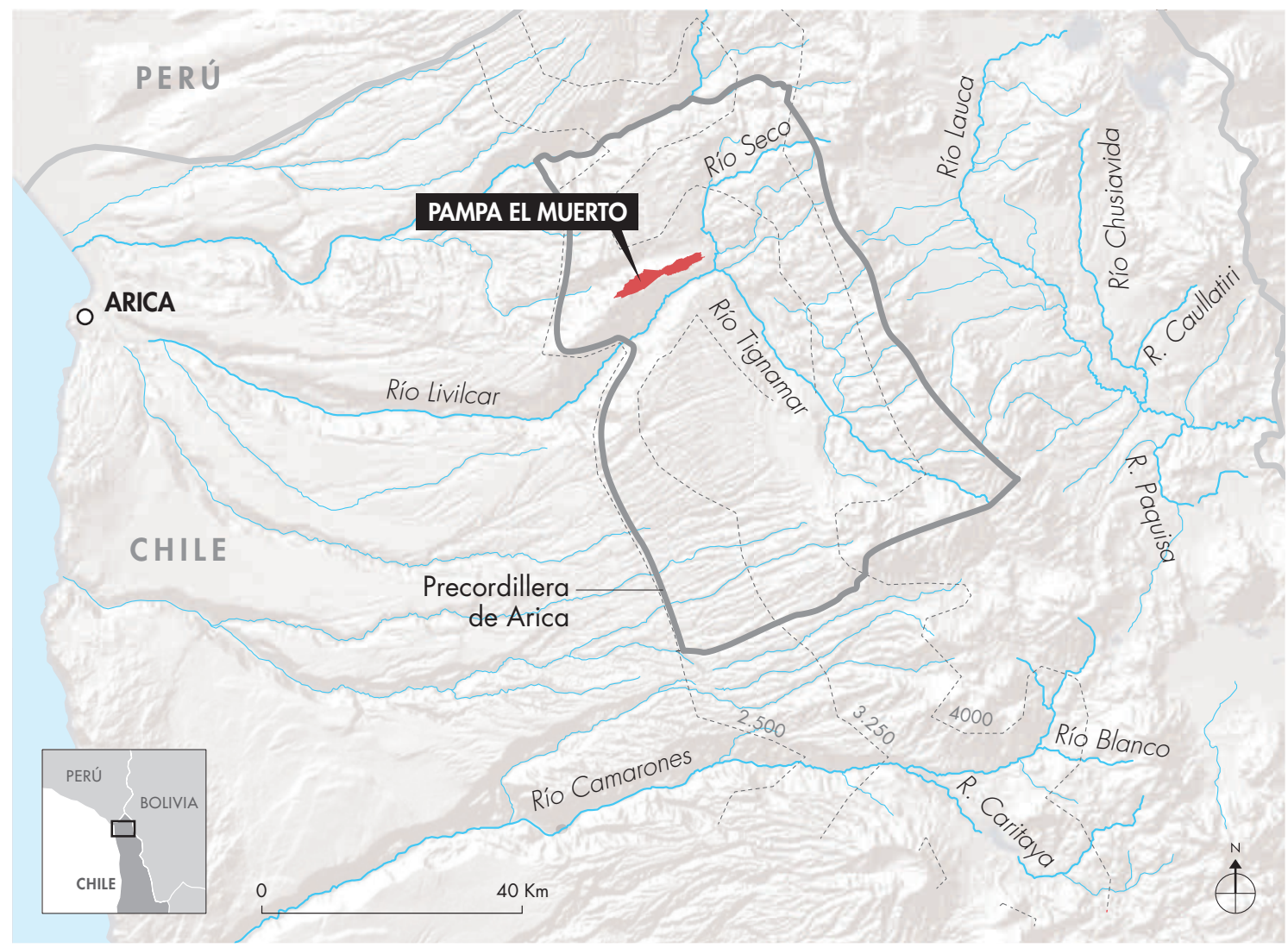

Figura 1. Mapa de ubicación del área de estudio. Figure 1. Map showing the area of study.

logra mediante excavaciones que permiten precisar las actividades asociadas; la obtención de fechados para afinar nuestra cronológica relativa; el estudio de la estratigrafía cromática presente en los paneles y una lectura de los motivos y escenas representadas. Finalmente, los resultados de PM-11 son discutidos a la luz de la información arqueológica del sector, que reiteran y confirman su uso como un significativo espacio de tránsito desde el Arcaico Temprano, hace aproximadamente 10.500 años, hasta tiempos coloniales.

\section{EL SECTOR PAMPA EL MUERTO DE LA PRECORDILLERA DE ARICA: GEOMORFOLOGÍA Y SÍNTESIS ARQUEOLÓGICA}

La sierra o precordillera de Arica, entre 2500 a 3800 msnm, corresponde a una franja angosta entre 20 a $35 \mathrm{~km}$ de ancho (Sepúlveda et al. 2013). Geomorfológicamente, Pampa El
Muerto (fig. 1), entre 2900 y 3400 msnm, se localiza en el sector de la meseta precordillerana, dorsal estrecha delimitada por la Quebrada de Cardones al norte, el río San José al sur y la confluencia de los ríos Tignamar y Seco con el río San José. En el sector predominan tobas ácidas que forman parte de una unidad de extensión regional conocida como Formación Ignimbrita-Oxaya. Como consecuencia de fenómenos de alteración de las rocas ignimbríticas, en las laderas de las quebradas se generan formas geomorfológicas conocidas como tafonis, poco estudiadas en la zona, que básicamente corresponden a aleros, algunos de ellos ocupados por los grupos humanos que transitaron por Pampa El Muerto (fig. 2). Se considera que su formación varía en función de la litología, la presencia de sales, el clima y la exposición (Groom et al. 2015). Más específicamente, algunos de los procesos evocados para explicar la desagregación de las rocas que conduce a la formación de estos tafonis son la precipitación directa, la humedad y la acción salina (Smith 2009). 

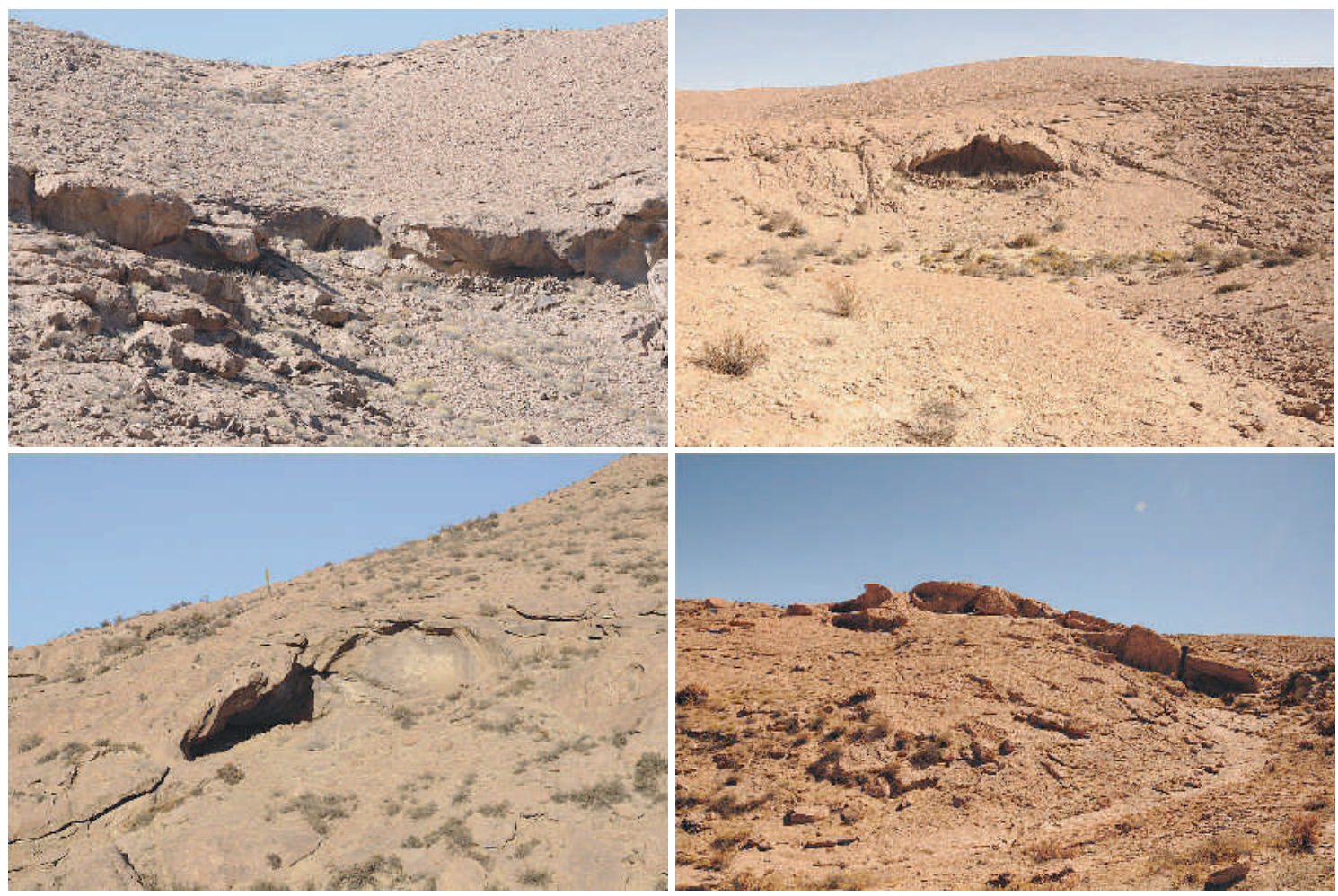

Figura 2. Ejemplos de tafonis (aleros) con arte rupestre en el sector Pampa El Muerto: a) PM -1; b) PM -2; c) PM-7; d) PM-11. Figure 2. Some tafonis (rock shelters) with rock art in the Pampa El Muerto sector: a) $P M-1 ; b) P M-2 ; c) P M-7 ; d) P M-11$.

Los 19 aleros del sector se emplazan en una quebrada menor con escurrimientos fluviales esporádicos que sustentan complejos vegetacionales de prepuna (1540-2800 msnm) y puna (3000-4000 msnm) (Villagrán et al. 1982, 1998, 1999), particularmente atractivos para camélidos en determinadas épocas del año, vizcachas y una importante cantidad de roedores y aves aún visibles. Actualmente, en este sector se sitúa el monumento natural Quebrada de Cardones, a cargo de conaf.

Entre los años 2006 y 2013, Pampa El Muerto fue explorada pedestremente en reiteradas ocasiones. Las primeras veces como reconocimientos dirigidos a la re-localización de los sitios ya identificados en décadas anteriores (Santoro 1992 Ms, Santoro \& Dauelsberg 1985, Muñoz \& Briones 1996). Luego, de manera más sistemática, para caracterizar la ocupación del sector en torno a los sitios de arte rupestre. En resumen, se prospectaron 93 ha, equivalentes al 15\% del área del sector, identificándose 219 sitios: aleros con o sin pircado $\mathrm{y}$ con o sin arte rupestre, estructuras tipo paravientos, afloramientos de materia prima con desechos de talla dispersos, eventos de talla, caminos, apachetas y estructuras de "muros-y-cajas".

La excavación y obtención de fechados en siete sitios (tabla 1), así como las evidencias arqueológicas documentadas en las inmediaciones del área de estudio, muestran la frecuentación del sector por los grupos humanos durante un amplio lapso de tiempo; no obstante, la mayor parte de las dataciones disponibles se ubican en los períodos Arcaico (10.500-3700 años AP) y Formativo (3700-1500 años AP), dado el énfasis de las investigaciones ahí desarrolladas.

Para el Arcaico Temprano (10.500-8000 años AP) se dispone de un fechado en el nivel 13 del alero PM-15, relativo a una ocupación de carácter logístico (Osorio et al. 2016). También en este alero, una datación procedente del nivel 9 muestra el uso temporal del sitio a fines de esa misma fase, con una mayor intensidad ocupacional respecto del período anterior (Osorio et al. 2016). Estas dataciones son coincidentes con otras obtenidas recientemente en el sitio a cielo abierto La Puerta, que muestran una mayor diversidad de ocupaciones entre 
Tabla 1. Fechados radiocarbónicos no calibrados procedentes de contextos arqueológicos inmediatos a paneles pintados en el sector pampa El Muerto. La calibración de estos fechados permitiría su adscripción cronológica a la fase arqueológica correspondiente. Table 1. Uncalibrated radiocarbon datings obtained from archeological contexts situated next to painted panels in the Pampa El Muerto sector. Once calibrated, the contexts can be chronologically assigned to the corresponding archeological stage.

\begin{tabular}{|c|c|c|c|c|c|c|c|}
\hline PERÍODO & $\begin{array}{l}\text { ALERO/ } \\
\text { SITIO }\end{array}$ & CÓDIGO & AÑOS AP & ${ }^{13} \mathrm{C} /{ }^{12} \mathrm{C}$ & CONTEXTO & $\begin{array}{l}\text { MATERIAL } \\
\text { FECHADO }\end{array}$ & REFERENCIA \\
\hline \multirow{4}{*}{$\begin{array}{c}\text { ARCAICO } \\
\text { TEMPRANO }\end{array}$} & 15 & BETA-319884 & $9510 \pm 95$ & $\begin{array}{l}-14,1 \\
0 / 00\end{array}$ & $\begin{array}{c}\text { Pozo 2. Capa } 4 . \\
\text { Nivel } 1\end{array}$ & $\begin{array}{c}\text { Óseo } \\
\text { quemado }\end{array}$ & $\begin{array}{l}\text { FONDECYT } \\
1100354\end{array}$ \\
\hline & La Puerta & BETA-441607 & $8260 \pm 30$ & & $\begin{array}{c}\text { Cuadrícula } 1 . \\
\text { Extensión Norte. } \\
\text { Capa } 2 \text { B }\end{array}$ & Carbón & $\begin{array}{l}\text { FONDECYT } \\
1130808\end{array}$ \\
\hline & 15 & BETA-35686 & $8190 \pm 30$ & $\begin{array}{l}-17,0 \\
0 / 00\end{array}$ & $\begin{array}{c}\text { Cuadrícula } 1 . \\
\text { Nivel } 9\end{array}$ & $\begin{array}{c}\text { Óseo } \\
\text { quemado }\end{array}$ & $\begin{array}{c}\text { FONDECYT } \\
1100354\end{array}$ \\
\hline & La Puerta & BETA-428146 & $7950 \pm 30$ & & $\begin{array}{c}\text { Sector E. } \\
\text { Cuadrícula } 11 . \\
\text { Nivel 4 D }\end{array}$ & Carbón & $\begin{array}{l}\text { FONDECYT } \\
1130808\end{array}$ \\
\hline \multirow{3}{*}{$\begin{array}{l}\text { ARCAICO } \\
\text { TARDÍO }\end{array}$} & 8 & UGAMS-3039 & $5750 \pm 30$ & $\begin{array}{l}-11,0 \\
0 / 00\end{array}$ & $\begin{array}{l}\text { Cuadrícula A3. } \\
\text { Capa II. Nivel } 2\end{array}$ & Carbón & $\begin{array}{l}\text { FONDECYT } \\
11060144\end{array}$ \\
\hline & 12 & BETA-361537 & $4440 \pm 30$ & & $\begin{array}{l}\text { Cuadrícula } 2 . \\
\text { Nivel B. Capa } 1\end{array}$ & $\begin{array}{l}\text { Sedimento } \\
\text { carbonoso }\end{array}$ & $\begin{array}{l}\text { FONDECYT } \\
1130808\end{array}$ \\
\hline & 11 & BETA-41882 & $4150 \pm 30$ & $\begin{array}{l}-11,5 \\
0 / 00\end{array}$ & $\begin{array}{c}\text { Pozo } 1 . \\
\text { Cuadrante SE. } \\
\text { Capa 3. Nivel E }\end{array}$ & Carbón & $\begin{array}{c}\text { FONDECYT } \\
1130808\end{array}$ \\
\hline \multirow{5}{*}{ FORMATIVO } & 2 & BETA-24356 & $2630 \pm 50$ & & $\begin{array}{c}\text { Cuadrícula } 1 . \\
\text { Nivel } 8\end{array}$ & Carbón & $\begin{array}{l}\text { Santoro } \\
\text { Com. Per. }\end{array}$ \\
\hline & 3 & UGAMS-3043 & $2460 \pm 30$ & & $\begin{array}{l}\text { Cuadrícula } 5 . \\
\text { Capa III. } \\
\text { Nivel 1. Rasgo } 6\end{array}$ & Carbón & $\begin{array}{c}\text { FONDECYT } \\
11060144\end{array}$ \\
\hline & 3 & UGAMS-3042 & $2180 \pm 30$ & & $\begin{array}{c}\text { Cuadrícula } 5 . \\
\text { Capa II. Nivel } 3 . \\
\text { Rasgo } 2\end{array}$ & Carbón & $\begin{array}{c}\text { FONDECYT } \\
11060144\end{array}$ \\
\hline & 8 & UGAMS-3040 & $1680 \pm 25$ & $\begin{array}{l}-22,1 \\
0 / 00\end{array}$ & $\begin{array}{c}\text { Cuadrícula B4/ } \\
\text { Pozo 1. Capa II. } \\
\text { Nivel } 1\end{array}$ & Carbón & $\begin{array}{l}\text { FONDECYT } \\
11060144\end{array}$ \\
\hline & 15 & BETA-335685 & $1530 \pm 30$ & $\begin{array}{c}-14.9 \\
0 / 00\end{array}$ & $\begin{array}{c}\text { Cuadrícula } 1 . \\
\text { Nivel } 4\end{array}$ & Óseo & $\begin{array}{l}\text { FONDECYT } \\
1100354\end{array}$ \\
\hline \multirow{2}{*}{$\begin{array}{l}\text { INTERMEDIO } \\
\text { TARDÍO Y } \\
\text { TARDÍO }\end{array}$} & La Puerta & BETA-361535 & $1040 \pm 30$ & & $\begin{array}{l}\text { Pozo 6. Nivel B. } \\
\text { Estrato } 3\end{array}$ & $\begin{array}{l}\text { Sedimento } \\
\text { carbonoso }\end{array}$ & $\begin{array}{l}\text { FONDECYT } \\
1130808\end{array}$ \\
\hline & 3 & UGAMS-3041 & $430 \pm 25$ & & $\begin{array}{l}\text { Cuadrícula } 5 . \\
\text { Capa II. } \\
\text { Nivel 1. Rasgo } 1\end{array}$ & Carbón & $\begin{array}{l}\text { FONDECYT } \\
11060144\end{array}$ \\
\hline
\end{tabular}




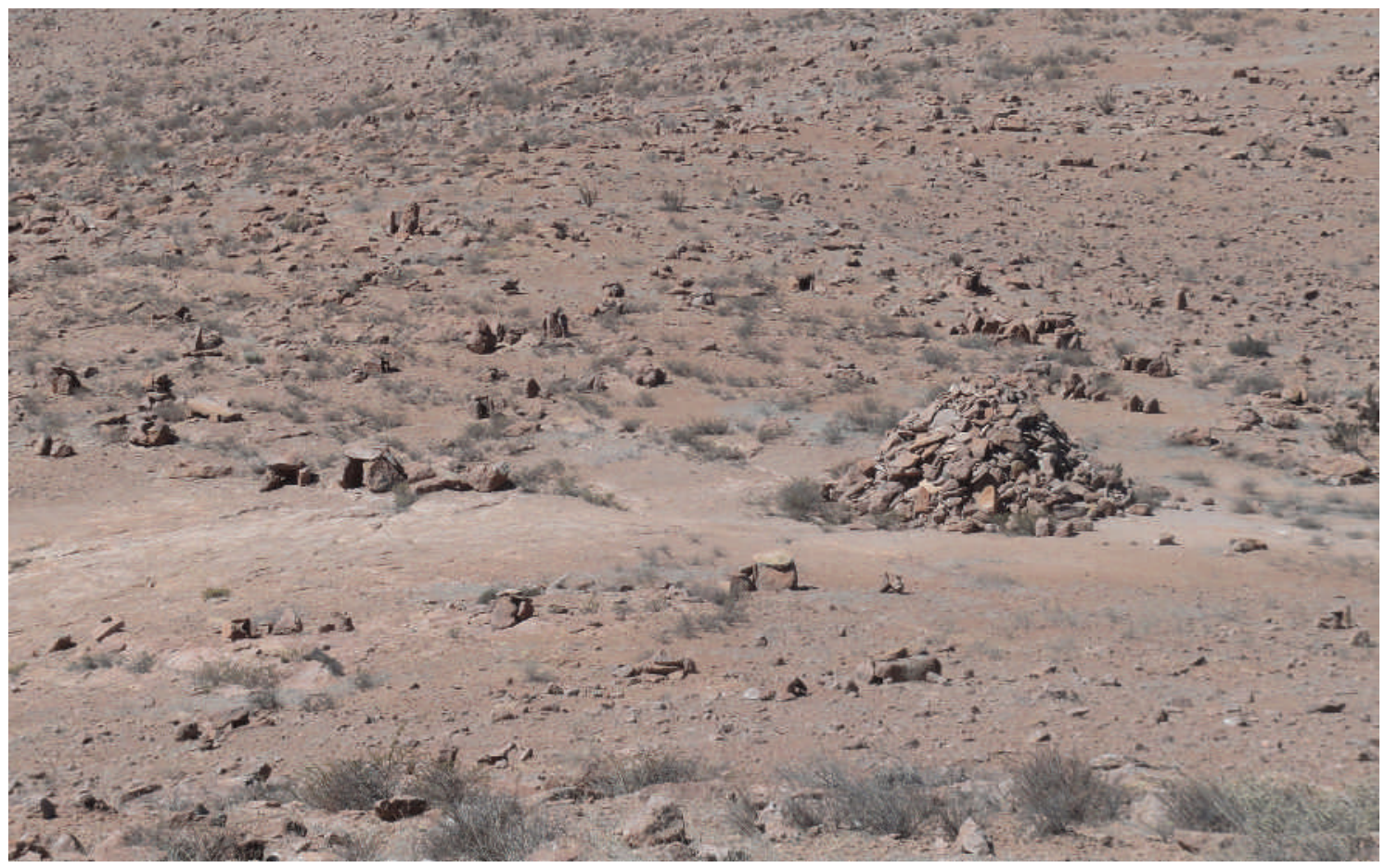

Figura 3. Vista general de las estructuras descritas, apachetas y "cajas". Figure 3. View of the structures described in the text: apachetas (stone cairns) and cajas ('boxes').

las fases tempranas, complementando así el patrón de asentamiento de grupos cazadores-recolectores. Una fecha en PM- 8 indica su uso a finales de la fase media en su transición hacia el Arcaico Tardío (6000-3700 años AP), lo que, sumado a dos fechas obtenidas en PM-11 y PM-12, permite insistir en el mantenimiento del uso de estos aleros hasta finales del Arcaico. En todos los casos se trata de ocupaciones logísticas de corta duración, posiblemente relacionadas con la caza de camélidos, aún visibles estacionalmente en el sector, o con la pernoctación antes de proseguir camino hacia otras localidades (Sepúlveda et al. 2013, 2018; Osorio et al. 2016). Cinco fechados obtenidos en PM-2, PM-3, PM- 8 y PM- 15 con arte rupestre, coinciden con tiempos Formativos, posterior a 3700 años AP (Sepúlveda et al. 2018). Destaca PM-3 con una mayor variabilidad de actividades definidas por la presencia de múltiples artefactos formatizados (mano de moler, preformas, puntas de proyectil, una muesca y un raspador), asociados a un conjunto de eventos de quema; y PM-15 donde, además de artefactos, se evidenciaron variadas semillas y un zuro de maíz, dando cuenta en ambos casos de la introducción de prácticas ligadas a cultígenos (Sepúlveda et al. 2018). Dos fechas de La Puerta y PM-3 evidencian finalmente la presencia de ocupaciones durante los períodos tardíos de la secuencia prehispánica regional (siglos XI-XVI) e incluso post-contacto, confirmadas por la presencia dispersa de fragmentos cerámicos decorados del período Intermedio Tardío y torneados de época colonial en distintos sectores de Pampa El Muerto.

En la zona no se registraron asentamientos tardíos habitacionales, siendo el pukara de Copaquilla el sitio de carácter aldeano más cercano (Schiappacasse et al. 1989, Muñoz \& Chacama 2006, Saintenoy et al. 2017). La presencia de importantes rutas troperas y de caravanas, e infraestructuras asociadas a esta actividad especializada de intercambio a larga distancia (Nielsen 1997, Berenguer 2004a), tales como paravientos semicirculares de pirca, montículos de piedras o apachetas, y "cajas" aisladas de carácter ceremonial (Berenguer 2004a, Pimentel 2009: 21) (fig. 3), más comunes en otras regiones del desierto de Atacama, confirmarían entonces el uso de Pampa El Muerto como lugar de paso, idea previamente sustentada con relación a la "Ruta Transversal Azapa № 3", que "bordea la pampa de Zapahuira hasta el sector de Pampa El Muerto, pasando por apachetas y markas" 
Tabla 2. Propuesta metodológica para las tres escalas de análisis definidas. Table 2. Proposed methodology for the three scales of analysis.

\begin{tabular}{c|c|c|c|c}
\multirow{2}{*}{ ESCALA } & NIVEL & $\begin{array}{c}\text { UNIDAD DE } \\
\text { LONGITUD }\end{array}$ & HITOS \\
\hline Micro & Motivo & Centímetro $(\mathrm{cm})$ & Tipología & Forma, tecnología y parámetros métricos \\
\hline Meso & Panel & Metro $(\mathrm{m})$ & Patrón de representación & $\begin{array}{c}\text { Topografía, composición, superposiciones } \\
\text { y estratigrafía cromática }\end{array}$ \\
\hline Macro & Sitio & Kilómetro $(\mathrm{km})$ & Grupo estilístico o estilo & Contexto, materiales culturales y fechados
\end{tabular}

(Muñoz \& Briones 1996: 62), hacia la costa por la vertiente del valle de Azapa. En este contexto, el pukara de Copaquilla pudo haber actuado como punto clave en la red de tráfico de caravanas, según los vestigios documentados en el sector.

Esta función de Pampa El Muerto se prolongaría en tiempos históricos coloniales (Muñoz \& Briones 1996, Choque \& Muñoz 2016), dada la identificación de caminos reales y distintos tramos locales -edificados sobre rutas prehispánicas (Dauelsberg 1983, Duffait 2012)-, destinados básicamente a la movilización de productos agropecuarios y manufacturas entre los siglos XVI a XVIII. Entre estos destaca el camino local numerado como 20, descrito por Choque y Muñoz (2016: 73) como una ruta árida que atraviesa Pampa El Muerto y que fue usada ocasionalmente dada la ausencia de recursos hídricos permanentes.

\section{Escalas y niveles de análisis del arte rupestre}

El estudio histórico del arte rupestre del extremo norte de Chile muestra el uso dispar de definiciones metodológicas en el desarrollo de la investigación. De ahí entonces la importancia de detallar los niveles que se emplearán, dado el conjunto de limitaciones interpretativas inherentes a cada escala analítica (Hyder 2004). Con el objetivo de disponer de una metodología susceptible de ser aplicada en estudios posteriores, se especificaron tres escalas y niveles de análisis jerárquicos definidos para el estudio de PM-11, desde un nivel micro a macro (Butzer 1982: 38). Estas escalas son físicas, por lo que se asocian con unidades de longitud (Chippindale 2004): micro-centímetro, escala más pequeña que se corresponde con los distintos tipos de motivos; meso-metro, de mayor magnitud, consistente en la relación entre motivos y cómo se distribuyen en los soportes rocosos, y macro-kilómetro, escala mayor referida a la localización de los aleros en el paisaje y su relación con las evidencias arqueológicas disponibles en el sector (tabla 2).

Más específicamente, la escala micro incluye la descripción formal de los motivos (forma, técnica y parámetros métricos) y atributos, como la representatividad, forma básica (Sepúlveda 2014), postura, perspectiva y animación, ya que el objetivo de este nivel es discernir los motivos individuales y clasificarlos tipológicamente mediante la búsqueda de analogías entre los atributos (Gallardo 1996). La escala meso se centra en la identificación de convenciones gráficas significativas, es decir, aproximación a las normas de construcción del panel. El análisis anterior posibilita la comparación de variables topográficas entre sitios, aportando información para conocer aspectos sobre la selección preferencial de determinados soportes (parámetros métricos, localización, tipo de iluminación, forma del soporte, alteraciones), la composición escénica (Gallardo 2009) y la ordenación en fases de elaboración (sincronía o diacronía) mediante el estudio de superposiciones (Schaafsma 1985). En el sector, las representaciones se asocian generalmente mediante yuxtaposición, por lo que se tuvo en cuenta el color como atributo de clasificación complementario para establecer las fases de ejecución, ya que, según Du- 
dognon y Sepúlveda (2018), en los sitios del valle de Lluta la mayoría de los motivos están dominados por una paleta reducida de colores que siguen un patrón constante de superposición o estratigrafía cromática.

Finalmente, estas dos escalas se integran en una tercera de mayor magnitud a nivel de sitio o macro, cuyo objetivo es observar la distribución espacial de los patrones de presentación en el sector (altura, orientación, características generales del paisaje, recursos hídricos), y su posible función a partir de los contextos arqueológicos asociados, en busca de patrones o cambios en las prácticas sociales y culturales. Aquí el estilo o grupo estilístico es visto como un elemento activo de la práctica social, pues informa acerca de los contextos (Conkey \& Hastorf 1990), por ejemplo, de uso o consumo. Para disponer de una terminología homogénea en el área de estudio y rescatar la variabilidad estilística, se proponen los conceptos operativos de grupo estilístico (GE) (Aschero 2006, Sepúlveda et al. 2010, 2013), es decir "patrones de representación, temas, selecciones de emplazamiento y uso de los soportes semejantes, ocurridos en una trama de relaciones relativamente sincrónica" (Aschero 2010: 110 ), y variante estilística (VE), entendida como particularidades formales y de composición escénica dentro de los GE. En la ordenación de los GE se entenderá que su superposición puede suponer un cambio de la práctica rupestre (Chaloupka 1993, Sieveking 1993), en términos cronológicos y también sociales.

Para nuestro estudio, y dada la necesidad de precisar las superposiciones, realizamos registros mediante técnicas digitales de documentación e interpretación (Cerrillo-Cuenca et al. 2014, Cerrillo-Cuenca 2015, Cerrillo-Cuenca \& Sepúlveda 2015, Guerrero et al. 2015). Esta metodología se apoya fundamentalmente en dos pasos: 1) la obtención de orto-imágenes a partir de fotogrametría, y 2) el procesamiento digital de la imagen para obtener el calco, es decir, realce de las pinturas y creación de calcos a partir de la orto-imagen mediante el software PyDRA (fig. 4).

\section{El arte rupestre de Pampa El Muerto 11}

El estudio consideró 80 motivos distribuidos en tres paneles (fig. 5), clasificados en tres categorías generales en función de sus características formales (Troncoso 2002; Sepúlveda 2014). Los zoomorfos son el tipo más común $(\mathrm{n}=50)$, con predominio de representaciones de camélidos $(\mathrm{n}=37)$, seguido de cuadrúpedos
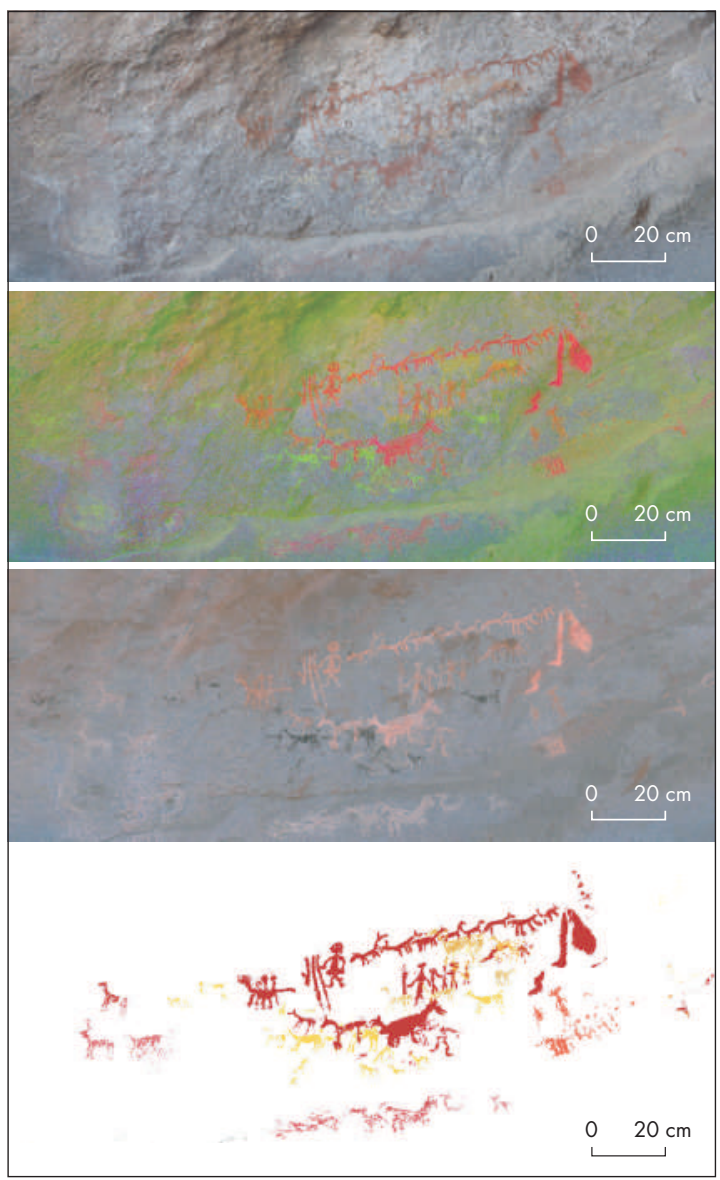

Figura 4. Imágenes generadas a partir del proceso descrito mediante el software PyDRA en PM-11: a) orto-imagen del Panel 1; b) DS; c) sIvc (x 1/4 1); d) calco final. Figure 4. Images of PM-11 generated using PYDRA software, as described in the text: a) orthoimage of Panel $1 ; b)$ DS; c) SIVC (x 1/4 1); d) final image.

indeterminados $(\mathrm{n}=10)$, un felino $(\mathrm{n}=1)$ y dos figuras que hasta el momento no habían sido descritas en la cuenca alta del río Tignamar, un cánido $(\mathrm{n}=1)$ y un posible pez $(\mathrm{n}=1)$. Las otras categorías tipológicas corresponden a antropomorfos $(n=21)$ y rastros $(n=9)$. Tecnológicamente, las representaciones fueron realizadas exclusivamente mediante la aplicación de pintura roja, amarilla o naranja, con sus correspondientes variaciones tonales. A partir de las características tenidas en cuenta en el análisis a nivel de motivo (micro escala) y de panel (meso escala), se propone la ordenación de las pinturas en dos patrones de representación. 

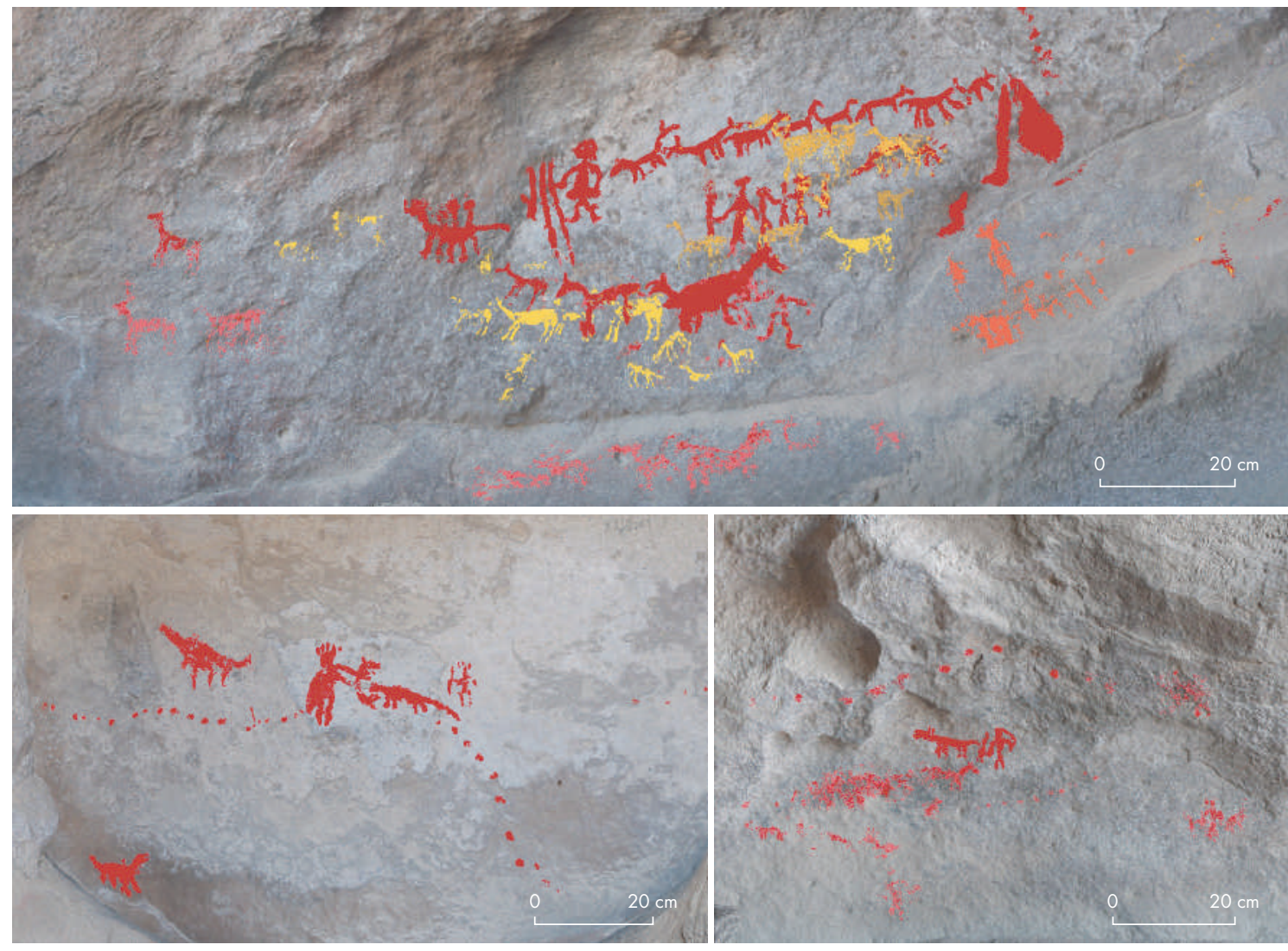

Figura 5. Pinturas rupestres en PM-11: a) panel 1; b) panel 2; panel 3. Figure 5. Rock paintings at PM-11: a) panel 1; b) panel 2; panel 3.

\section{Grupo estilístico 1 (GE-1)}

El GE-1 está caracterizado por camélidos, antropomorfos y rastros, en colores amarillo y naranja. Los camélidos fueron representados con rasgos anatómicos detallados, tales como orejas redondeadas, separadas entre sí formando una "U", cuello proyectado hacia delante que permite la posición alta de la cabeza y una marcada línea dorsal que termina en una cola redondeada dispuesta hacia abajo. Además, presentan una acusada curva ventral que define el vientre y enfatiza los cuartos traseros del animal, así como rasgos musculares detallados, articulación de las patas y pezuñas. Estos camélidos, con una dimensión de hasta $17 \mathrm{~cm}$, participan en escenas de caza dispuestos aleatoriamente en actitud de carrera, evidenciada por la disposición entreabierta y flectada de sus extremidades delanteras y traseras. Por otro lado, los motivos antropomorfos, con una dimensión menor a $5 \mathrm{~cm}$, se representan esquemáticamente, es decir, sin rasgos anatómicos detallados, dispuestos aleatoriamente en actitud dinámica de disparo. Algunos de ellos aparecen blandiendo propulsores y dardos en sus manos, y con tocados, formados por dos trazos lineales de tendencia diagonal.

Con base en las particularidades formales y la composición escénica, en este patrón se identificó una variante estilística (variante 1-1), formada por camélidos estáticos, con pérdida de detalle en la expresión de los rasgos musculares y la articulación de las patas, aunque se destaca el vientre a través del estrechamiento de la línea ventral. La variante se caracteriza por una dimensión más equitativa de motivos zoomorfos y antropomorfos, que no superan los $7 \mathrm{~cm}$ y $5 \mathrm{~cm}$, respectivamente, y un número reducido de figuras $(\mathrm{n}=4)$, asociadas mediante yuxtaposición, en escenas donde los antropomorfos "persiguen" animales, aparentemente sin elementos arrojadizos de caza terrestre en sus manos. 

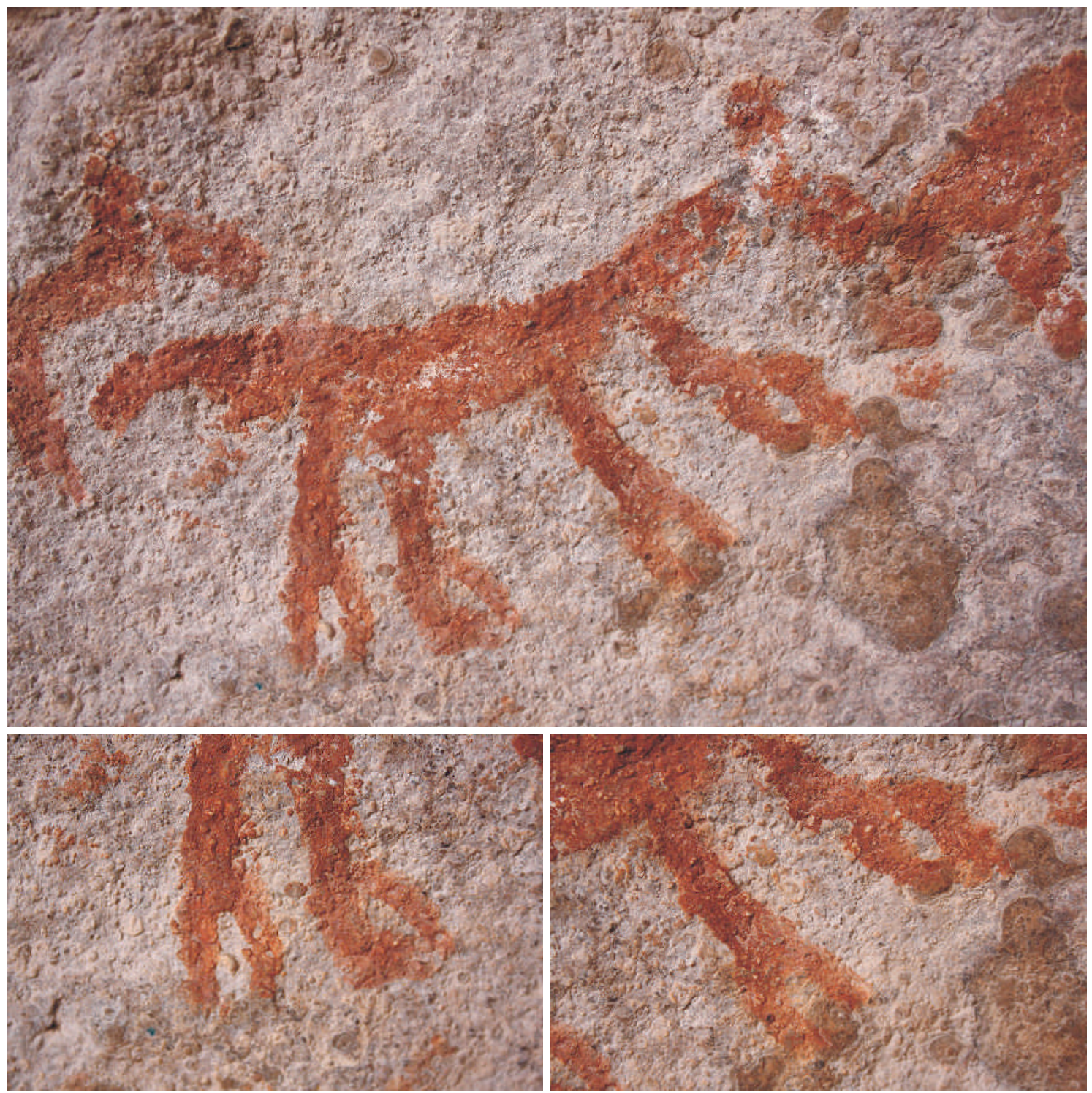

Figura 6. Camélido del GE-2. Detalle de pezuñas en extremidades delanteras y traseras. Figure 6. Camelid from GE-2. Close-up of toes on front and back legs.

\section{Grupo estilístico 2 (GE-2)}

El GE-2 reúne exclusivamente pinturas en color rojo. En este GE los camélidos se plasman de perfil, sin dinamismo, ni rasgos anatómicos detallados, dispuestos en hilera y con una dimensión menor a $13 \mathrm{~cm}$. En algunos casos se documenta la estrecha yuxtaposición entre la cola y el cuello del camélido anterior, pezuñas (fig. 6), así como camélidos bicápites, recurso gráfico exclusivo del GE-2. Escénicamente, los motivos antropomorfos se muestran más dinámicos junto a camélidos que presentan una mayor rigidez, en temáticas pastoriles de control, direccionamiento y dominación de estos animales.

No obstante la tendencia al esquematismo entre los motivos animales, se documenta una mayor diversidad de especies endémicas regionales, un felino, un cánido y un pez. El felino de dimensión de $6,61 \mathrm{~cm}$ de alto y $15,33 \mathrm{~cm}$ de largo, está de perfil y de pie sobre las cuatro extremidades, con dos orejas de morfología redondeada, hocico corto y cola particularmente alargada. La pintura 



Figura 7. Antropomorfo del GE-2 con representación de adornos corporales (tocado, elementos de rodilla y faldellín) blandiendo elementos longitudinales. Figure 7. Anthropomorphic figure from GE-2 with decorative elements (headdress, knee ornaments and girdle), wielding long items.

interpretada como cánido mide $8,87 \mathrm{~cm}$ de alto y 4,5 $\mathrm{cm}$ de largo, también de perfil, presenta una cabeza de morfología rectangular, una oreja puntiaguda y alargada hacia arriba, y es sostenido en el aire por una figura humana que le confiere posición erecta. En último lugar, la figura interpretada como pez mide $8,97 \mathrm{~cm}$ de alto y $39,96 \mathrm{~cm}$ de largo, se encuentra de perfil en disposición hacia la izquierda sobre una concavidad natural, generando extrema rigidez en la estructura anatómica, dada la adecuación del animal a la morfología rocosa. Respecto de la estructura corporal, destaca la representación casi exclusiva de escamas o espinas interiores a partir de trazos longitudinales de recorrido paralelo, dispuestos verticalmente y de grosor variable. La cabeza fue hecha mediante tres trazos de mayor grosor que los empleados para la elaboración interior, de la misma manera que la aleta caudal ubicada en la cola.

Los antropomorfos se disponen de frente, adquiriendo un naturalismo mayor en el detalle de los rasgos anatómicos, así como una mayor dimensión, superior a $10 \mathrm{~cm}$. Además, destaca una mayor gama de elementos de ornamento y adorno corporal (tocados, túnicas, elementos de rodilla y faldellín) y elementos longitudinales en sus manos (fig. 7).

\section{DISCUSIÓN}

Los atributos analizados a diferentes escalas en PM-11 evidencian dos patrones de representación contrastados, GE-1 y GE-2, de acuerdo con las definiciones realizadas en otros aleros precordilleranos (Sepúlveda 2011a; Sepúlveda et al. 2013). En términos de estratigrafía gráfica, la superposición cromática registrada en PM-11 convierte este alero en un caso particular de estudio, ya que son escasas en el área. Se observaron así dos niveles de superposición: en el nivel basal se encuentran motivos en color amarillo y naranja, sobre los cuales se superpusieron motivos en rojo (fig. 8). Esta secuencia no coincide con la propuesta realizada para el valle de Lluta, donde el inicio de la actividad rupestre corresponde con escenas exclusivas de ma- 


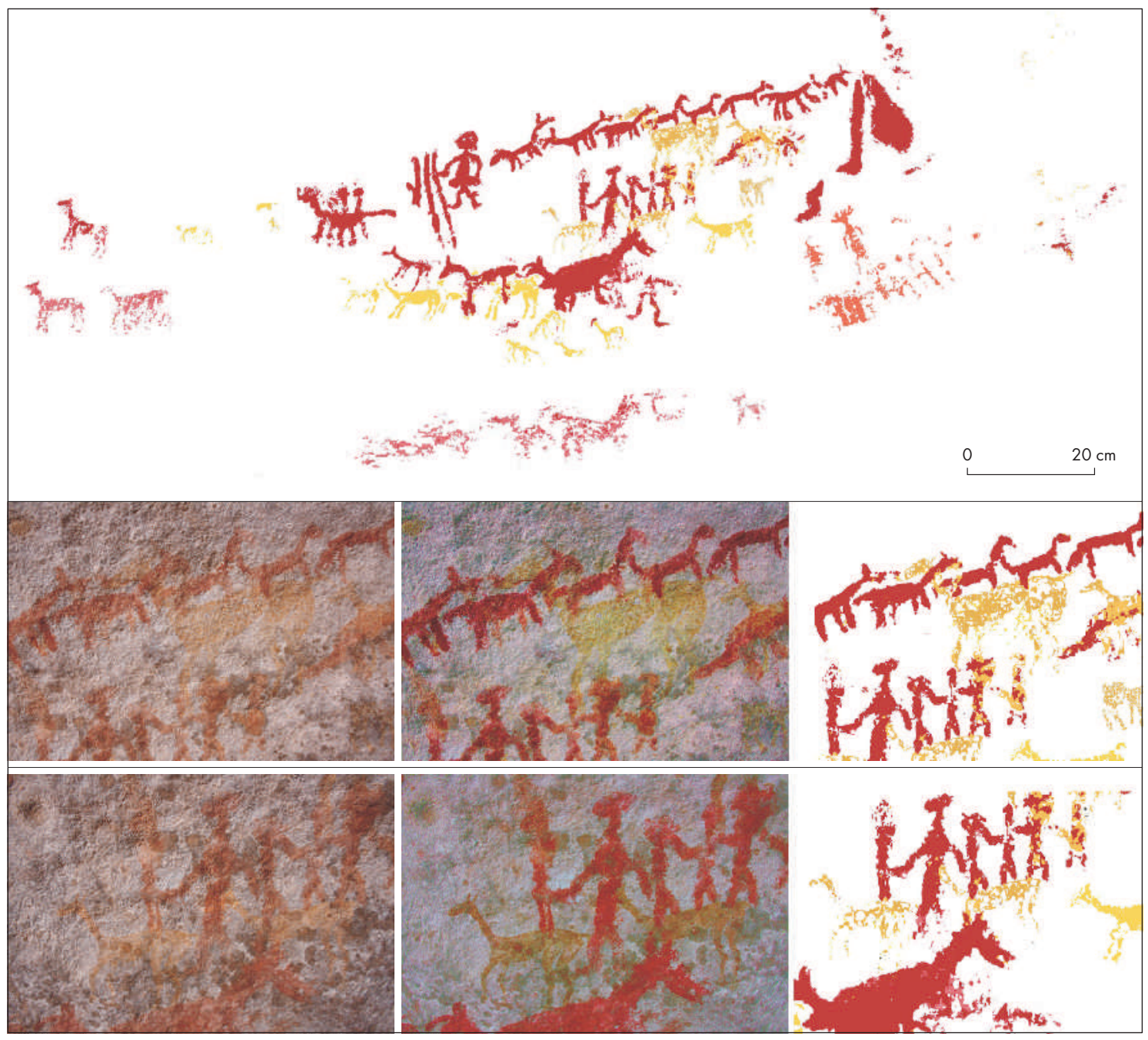

Figura 8. Detalle de superposiciones en el panel 1 de PM-11: camélidos naturalistas amarillos en escena de caza (GE-1) bajo camélidos esquemáticos rojos y antropomorfos con tocado en escena pastoril (GE-2). Figure 8. Detail of superimposed images on PM-11 panel 1: hunting scene with yellow-colored naturalistic camelids (GE-1) overlaid by red schematic camelids and anthropomorphic figures with headdresses in a pastoral scene (GE-2).

nadas de camélidos en color rojo oscuro (Dudognon \& Sepúlveda 2018), seguida de una fase con escenas de caza en color amarillo y naranja. De tener un valor cronológico relativo, las representaciones más antiguas en PM-11 corresponderían con la segunda fase de ejecución descrita para Lluta, lo que podría indicar un inicio posterior de la actividad gráfica en el sector, así como procesos rupestres diferenciados en las distintas cuencas del extremo norte de Chile.

En términos económicos, otra de las particularidades de este alero es la superposición escénica directa de temáticas relacionadas con modos de subsistencia distintos, tal como hemos interpretado: "escenas de caza" bajo "escenas pastoriles", secuencia común a lo observado en otras localidades de la región y del sur del Perú (Klarich \& Aldenderfer 2001).

\section{Arte rupestre de grupos cazadores- recolectores}

En el GE-1 los motivos incluyen antropomorfos representados mediante simples trazos junto a camélidos con rasgos anatómicos detallados, organizados en escenas de caza y con una marcada desproporción a favor de los 



Figura 9. Detalle de antropomorfos con tocado del GE-2: a) panel 1; b) panel 2. Figure 9. Detail of anthropomorphic figures with headdresses at $\mathrm{GE}-2: \boldsymbol{a}$ ) panel $1 ; \boldsymbol{b}$ ) panel 2.

zoomorfos, que exceden a los antropomorfos, tanto en número como en dimensión. En términos de superposición, corresponde con la fase más antigua de representación, asociada con el arte rupestre de tradición naturalista, a partir de similitudes en la temática, composición escénica y uso del color con otros conjuntos pintados del valle de Azapa (Sepúlveda 2008, 2011a; Sepúlveda et al. 2010, 2013), Lluta (Dudognon \& Sepúlveda 2018) y 
sur de Perú (Guffroy 1999; Klarich \& Aldenderfer 2001; Hostnig 2011, 2012, 2013).

En términos cronológicos, el GE-1 se adscribiría al Arcaico Tardío, momento de ocupación más intensiva y extensiva de las tierras altas por grupos de cazadoresrecolectores (Santoro et al. 2016) y de profusión e incremento de la actividad rupestre (Sepúlveda et al. 2013). La propuesta cronológica se apoya en tres fechados ${ }^{14} \mathrm{C}$ procedentes de los aleros PM- 8 , PM-11 y $\mathrm{PM}-12$, interpretados como campamentos logísticos de corta duración, orientados a actividades de reducción lítica (Sepúlveda et al. 2013, Osorio et al. 2016) y consumo de frutos de cactáceas (García \& Sepúlveda 2011). Contextualmente, estas evidencias parecen indicar que el uso de los aleros en Pampa El Muerto, a finales del Arcaico, estuvo destinado a la práctica rupestre, $\mathrm{y}$ a actividades de descanso, cuando se aprovechó además de reactivar ciertos artefactos líticos, durante un período caracterizado por importantes cambios socio-económicos en la región (Osorio et al. 2016, Sepúlveda et al. 2017).

\section{Arte rupestre de grupos pastoriles}

El GE-2 corresponde a motivos antropomorfos que adquieren una dimensión notablemente mayor respecto al GE-1, con elementos longitudinales en sus manos y atuendo, vinculadas escénicamente con camélidos sin dinamismo y menor detalle en su representación (Sepúlveda 2011a, Sepúlveda et al. 2013). Pensamos que las escenas pueden relacionarse con prácticas ligadas al pastoreo de camélidos domésticos, afirmación que se apoya en la disposición de control y direccionamiento de las figuras humanas sobre grupos de animales alineados. Además, la representación más equivalente entre patas delanteras y traseras de los camélidos coincide con la diferencia en las proporciones anatómicas entre camélidos silvestres y domésticos reportada en el arte rupestre del Formativo Temprano atacameño (Gallardo \& Yacobaccio 2005, 2007); aunque se requiere precisar con datos cuantitativos.

Otra característica del arte rupestre pastoril es la introducción de referentes faunísticos de presencia regional (Berenguer 1996, Klarich \& Aldenderfer 2001). Nos referimos en PM-11 a la presencia de un felino y un zorro, descrito previamente como un posible camélido juvenil en una escena con rasgos ceremoniales, quizás parte de un "acto propiciatorio", según Santoro y Dauelsberg (1985: 83). Con relación a la representación interpretada como pez, la presencia de objetos "misceláneos" alóctonos, en particular artículos costeros en ocupaciones de distintos períodos de la secuencia cronológica de tierras altas (Castillo \& Sepúlveda 2017, Castillo, comunicación personal 2017), sustentan conexiones entre las dos regiones. Si bien los peces no habían sido descritos hasta el momento en el arte rupestre precordillerano, los objetos litorales nos informan sobre interacciones permanentes y los consiguientes flujos de información expresados en forma de arte rupestre (Castillo \& Sepúlveda 2017, Sepúlveda et al. 2017). Adicionalmente, apostamos por una variabilidad tipológica mayor a la planteada, ya que siguiendo a Fiore (2011: 115), las formas "menos replicadas podrían haber sido sumamente valiosas para el grupo productor si se las encuentra ubicadas en determinadas porciones del soporte rocoso o artefactual, o en sitios con determinadas características de emplazamiento topográfico", como la oquedad natural empleada en el contorno de esta pintura.

En este grupo, la figura humana asume un papel central, evidenciado por el tamaño, detalle en la representación, además de la profusión de elementos ornamentales. Se observan tocados (fig. 9), usados inicialmente por grupos con actividades de subsistencia asociadas a las primeras prácticas agrícolas y a la domesticación del camélido (Agüero 1993, 1994, 1995; Bravo 1993), túnicas (sensu Ulloa 1985) que aparecen en contextos arqueológicos a partir del Período Formativo (Carmona 2006, Cases \& Montt 2013) y un posible faldellín, que avalaría una adscripción cronológica del Formativo, al menos en el desierto de Atacama (Montt 2002).

En términos cronológicos, pese a que hasta la fecha el estudio de la vestimenta textil y de los adornos corporales en el arte rupestre precordillerano no ha sido abordado sistemáticamente, la comparación con otros sectores del desierto de Atacama nos informa sobre la profusión de estos elementos desde finales del Arcaico y durante tiempos coincidentes con el Formativo. Además, la presencia de restos cerámicos de los períodos Intermedio Tardío y Tardío de la secuencia prehispánica regional (Uribe, comunicación personal 2017) y fibra animal hilada en los estratos superiores al datado de PM-11, puede ser interpretado como una continuación temporal en el uso de este alero, más allá del Arcaico.

Por lo tanto, la integración de diversas líneas de evidencia para el estudio de PM-11 en particular y del sector Pampa El Muerto en general, nos permite plantear una cronología relativa de los GE identificados durante 
dos momentos diacrónicos. En primer lugar, el inicio de actividad gráfica en el sector tendría lugar a finales del Arcaico, a propósito de una ocupación más intensiva de la precordillera por grupos cazadores-recolectores. Luego, directamente sobre las escenas de caza, grupos pastoriles realizarían representaciones de camélidos alineados sin carga, con preeminencia de la figura humana, que aparece representada con mayor naturalismo y detalle, confiriéndole un rol más protagónico respecto de los animales. Estas representaciones se asociarían con tiempos formativos en adelante.

\section{CONSIDERACIONES FINALES}

El análisis a diferentes escalas del alero PM-11 ha permitido a nivel de motivo (micro escala), individualizar y clasificar tipológicamente las representaciones. La disminución del grado de resolución muestra una heterogeneidad tipológica de los motivos zoomorfos y antropomorfos mayor a la descrita hasta el momento. En este sentido, se destaca la documentación de especies animales endémicas precordilleranas y la representación de rasgos anatómicos detallados y ornamentación en la figura humana. La información obtenida en este nivel permite realizar comparaciones más precisas con otros conjuntos pintados en tierras altas, a escala meso y macro.

A nivel de panel (meso escala), la variabilidad temática y de composición escénica caracterizan los dos patrones de representación diacrónicos. Estos patrones han sido ordenados en fases de ejecución mediante el estudio de superposiciones y estratigrafía cromática de la siguiente manera: un nivel basal y, por lo tanto, más antiguo, caracterizado por motivos en colores amarillo y naranja, en el que las figuras de camélidos y humanos se organizan en escenas de caza. En un segundo nivel, representaciones de camélidos, entre otros animales, y humanos en color rojo, se superponen dispuestos en escenas de pastoreo sobre el anterior. La comparación con otros conjuntos pintados en el valle de Lluta, muestra un uso diferencial del color entre esta cuenca y Azapa.

A nivel de sitio (macro escala), si bien los patrones de representación identificados (GE-1 y GE-2) coinciden con las definiciones enunciadas previamente para la precordillera de Arica, se han incorporado nuevos datos a la discusión y reevaluación de las definiciones estilísticas realizadas por investigaciones precedentes (Niemeyer
1972; Sepúlveda 2011a; Sepúlveda et al. 2010, 2013). Más aún, se ha avanzado en la superación de las dificultades señaladas para el estudio del arte rupestre del extremo norte de Chile, como también en la definición de estilos que permitan ordenar el arte rupestre, cronologías que integren un conjunto amplio de representaciones y la omisión de las variaciones microlocales, entre otras (Valenzuela et al. 2014: 444). En esta escala mayor se han precisado distinciones estilísticas a nivel de localidad que deben ser ampliadas mediante la integración de otros conjuntos de representaciones. Adicionalmente, se ha insertado la actividad rupestre en la secuencia regional mediante la asociación con los contextos arqueológicos y las dataciones disponibles para otros aleros. El estudio contextual del arte rupestre muestra la reiteración en el uso de este sector desde el Arcaico Temprano hasta tiempos tardíos, con ocupaciones breves temporales durante las cuales los grupos humanos marcan el espacio en forma de arte rupestre, especialmente a finales de este período, coincidente con los cambios socio-económicos que lo caracterizan. Además, ha permitido generar una primera instancia para discutir la atribución cronología relativa de los GE en dos momentos puntuales, a finales del Arcaico y desde el Formativo en adelante. Así, no se descarta la continuación de la actividad gráfica en momentos posteriores (Intermedio Tardío, por ejemplo), dado que la función arqueológica, como espacio de tránsito a través de las rutas que atraviesan el sector desde el altiplano hacia la costa y en la precordillera de norte a sur, parece no haber variado desde las primeras ocupaciones.

La discontinuidad en los patrones de representación en PM-11 y la apropiación del espacio gráfico a través de la superposición de escenas ligadas a la práctica pastoril sobre escenas de caza, muestran una atención particular sobre la representación de diferentes actividades y prácticas económicas, lo que puede asociarse con cambios ocurridos en las prácticas sociales e ideológicas, reproducidas en forma de estilo, elemento activo de la práctica social (Conkey \& Hastorf 1990; Gallardo 2001). En este sentido, destacamos el arte rupestre como materialidad válida para precisar procesos socio-culturales, económicos e ideológicos pasados, especialmente cuando se reproduce bajo determinadas normas y convenciones gráficas. Finalmente, el uso reiterado del alero pudo estar relacionado con la marcación rupestre del espacio por grupos culturales distintos, que proyectan su identidad como elemento de diferenciación social en forma de estilo; es decir, el arte rupestre es utilizado como 
mecanismo de diferenciación grupal en relación con transformaciones de las estrategias sociales ocurridas en la región a lo largo de la secuencia prehispánica, y quizás post-contacto. Nuevos y futuros antecedentes permitirán, sin duda, precisar más esta propuesta y las definiciones estilísticas para la precordillera de Arica.

Agradecimientos La realización de este trabajo fue posible gracias al financiamiento recibido por el Proyecto de Tesis de Investigación para Estudiantes de Programas de Postgrado UTA $N^{\circ}$ 8759-16. Deseamos expresar nuestro agradecimiento a estudiantes, profesionales e investigadores colaboradores de las diferentes campañas de prospección, excavación y relevamiento de arte rupestre. Especialmente a Marta Crespo, Luca Sitzia y Enrique Cerrillo-Cuenca, por el registro de los aleros, la descripción geomorfológica del sector y la realización de calcos en Pampa El Muerto, respectivamente. Nuestro reconocimiento a CONAF por permitirnos efectuar trabajos en el monumento natural Quebrada de Cardones, que comprende parte de los sitios estudiados en Pampa El Muerto. Finalmente, agradecer al Convenio de Desempeño UtA-MINEDUc por su apoyo a la realización de este trabajo.

\section{REFERENCIAS}

AgüEro, C. 1993. Análisis técnico de turbantes. En Identidad $y$ prestigio en los Andes: gorros, turbantes y diademas, F. Gallardo \& L. Cornejo, Eds., pp. 74-75. Santiago: Museo Chileno de Arte Precolombino.

Agüero, C. 1994. Clasificación de turbantes del Período Formativo Temprano en el norte de Chile. Boletín del Comité Nacional de Conservación Textil 2: 61-70. Santiago.

AgüERo, C. 1995. Indicadores textiles de grupos formativos: proposición de una tipología de turbantes. Hombre y desierto. Una perspectiva cultural 9: 97-114. Antofagasta.

Aschero, C. 2006. De cazadores y pastores. El arte rupestre de la modalidad río Punilla en Antofagasta de la Sierra (Puna meridional, Argentina). En Tramas en la piedra, D. Fiore \& M. Podestá, Eds., pp. 103-140. Buenos Aires: Asociación Amigos del Instituto Nacional de Antropología.

Aschero, C. 2010. Las escenas de caza en Cueva de las Manos: una perspectiva regional (Santa Cruz, Argentina). Préhistoire, art et sociétés: bulletin de la Société Préhistorique de l'Ariège 65-66: 807-823. Tarascon-sur-Ariège.

Ballester, B. \& Gallardo, F. 2016. Painting a lost world. The red rock art of El Médano. Current World Archaeology 77: 36-38. Londres.
Berenguer, J. 1996. Identificación de camélidos en el arte rupestre de Taira: ¿animales silvestres o domésticos? Chungara 28 (1-2): 85-114. Arica.

Berenguer, J. 2004a. Caravanas, interacción y cambio en el desierto de Atacama. Santiago: Sirawi.

Berenguer, J. 2004b. Cinco milenios de arte rupestre en los Andes atacameños: imágenes para lo humano, imágenes para lo divino. Boletín del Museo Chileno de Arte Precolombino 9: 75-108. Santiago.

Bravo, M. 1993. Gorros atacameños. En Identidad y prestigio en los Andes: gorros, turbantes y diademas, F. Gallardo \& L. Cornejo, Eds., pp. 76-81. Santiago: Museo Chileno de Arte Precolombino.

ButZer, K. 1982. Archaeology as human ecology: method and theory for a contextual approach. Cambridge: Cambridge University Press.

Carmona, G. 2006. Caracterización de las prendas textiles incas presentes en sitios arqueológicos tardíos del extremo norte de Chile. Memoria para optar al título de Arqueóloga. Departamento de Antropología, Facultad de Ciencias Sociales, Universidad de Chile, Santiago.

CAses, B. \& MontT, I. 2013. Las túnicas rupestres pintadas de la cuenca media y alta del Loa vistas desde Quillagua (norte de Chile). Chungara 45 (2): 249-275. Arica.

Castillo, C. \& Sepúlveda, M. 2017. Objetos "misceláneos" y dinámicas sociales en contextos de cazadores recolectores de la precordillera de Arica, extremo norte de Chile. Chungara 49 (2): 159-174. Arica.

Cerrillo-Cuenca, E. 2015. Algunas reflexiones sobre métodos de realce digital de la imagen en pinturas rupestres. Arqueología y prehistoria del interior peninsular 3: 119-132. Alcalá de Henares.

Cerrillo-Cuenca, E., Ortiz-Coder, P. \& Martínez del Pozo, J. 2014. Computer vision methods and rock art: towards a digital detection of pigments. Archaeological and Anthropological Sciences 6 (3): 227-239. Berlín-Heidelberg.

Cerrillo-Cuenca, E. \& Sepúlveda, M. 2015. An assessment of methods for the digital enhancement of rock paintings: the rock art from the precordillera of Arica (Chile) as a case study. Journal of Archaeological Science 55: 197-208. Londres.

ChaloupKa, G. 1993. You gotta have style. En Rock art studies: the post-stylistic era or where do we go from here?, M. Lorblanchet \& P. Bahn, Eds. pp. 77-98. Oxford: Oxbow Monographs.

Chippindale, C. 2004. From millimetre up to kilometre: a frameword of space and of scale for reporting and studying rock-art in its landscape. En The figured landscapes of rock-art: looking at pictures in place, C. Chippindale \& G. Nash, Eds., pp. 102-117. Cambridge: Cambridge University Press.

Choque, C. \& Muñoz, I. 2016. El camino real de la Plata. Circulación de mercancías e interacciones culturales en los valles y Altos de Arica (siglos XVI al XVIII). Historia 49 (1): 57-86. Santiago. 
Conkey, M. \& Hastorf, C. 1990. Introduction. En The uses of style in archaeology, M. Conckey \& C. Hastorf, Eds., pp. 1-4. Cambridge: Cambridge University Press.

Dauelsberg, P. 1983. Investigaciones arqueológicas en la sierra de Arica, sector Belén. Chungara 11: 63-83. Arica.

Dudognon, C. \& SepúlvedA, M. 2013. Hunting practices in rock art sierra Arica (far north of Chile). En proceedings of 25th Symposium of Valcamonica, pp. 237-242. Valcamonica. Capo di Ponte: Edizioni Del Centro.

Dudognon, C. \& Sepúlveda, M. 2018. Rock art of the upper Lluta valley, northernmost of Chile (south central Andes): a visual approach to socio-economic changes between Archaic and Formative periods (6000-1500 years вP). Quaternary International 491: 136-145.

Duffait, E. 2012. Vías prehispánicas y culto de los muertos en el norte chileno (Arica-Tarapacá) durante el Período Intermedio Tardío y el Horizonte Tardío (ca. 1000-1532 DC). Chungara 44 (4): 621-635. Arica.

FIORE, D. 2007. The economic side of rock art: concepts on the production of visual images. Rock Art Research 24 (2): 149-160. Darwin.

FIORE, D. 2011. Materialidad visual y arqueología de la imagen. Perspectivas conceptuales y propuestas metodológicas desde el sur de América. Boletín del Museo Chileno de Arte Precolombino 16 (2): 101-119. Santiago.

Gallardo, F. 1996. Acerca de la lógica en la interpretación del arte rupestre. Boletín de la Sociedad Chilena de Arqueología 23: 31-33. Santiago.

GALlardo, F. 2001. Arte rupestre y emplazamiento durante el Formativo Temprano en la cuenca del río Salado (desierto de Atacama, norte de Chile). Boletín del Museo Chileno de Arte Precolombino 8: 83-97. Santiago.

Gallardo, F. 2009. Sobre la composición y la disposición en el arte rupestre de Chile: consideraciones metodológicas e interpretativas. Magallania 37 (1): 85-98. Magallanes.

Gallardo, F., Montt, I., Sepúlveda, M. \& Pimentel, G. 2006. Nuevas perspectivas en el estudio del arte rupestre en Chile. Boletín de la Sociedad de Investigación del Arte Rupestre de Bolivia 20: 77-87. La Paz.

Gallardo, F. \& Yacobaccio, H. 2005. Wild or domesticated? Camelids in Early Formative rock art of the Atacama desert (northern Chile). Latin American Antiquity 16 (2): 115-130. Cambridge.

Gallardo, F. \& Yacobaccio, H. 2007. ¿Silvestres o domesticados? Camélidos en el arte rupestre del Formativo Temprano en el desierto de Atacama (norte de Chile). Boletín del Museo de Arte Precolombino 12 (2): 9-31. Santiago.

García, M. \& Sepúlveda, M. 2011. Contextos vegetales de aleros con pinturas (precordillera de Arica, norte de Chile). Estudios Atacameños 41: 97-118. San Pedro de Atacama.

Groom, K., Casey, D., Mol, L., Pardise, T. \& Hall, K. 2015. Defining tafoni: re-examining terminological ambiguity for cavernous rock decay phenomena. Progress in Physical Geography 39 (6): 775-793. California.
Guerrero, Z. 2016. Análisis a micro escala de las pinturas rupestres del sector Pampa El Muerto de la precordillera de Arica, extremo norte de Chile. Tesis para optar al grado de Magíster en Antropología, Mención Arqueología. Departamento de Antropología, Universidad de Tarapacá-Universidad Católica del Norte, Arica-San Pedro de Atacama.

Guerrero, Z., Sepúlveda, M. \& Cerrillo-Cuenca, E. 2015. Aproximación mediante técnicas digitales de documentación al estudio del arte rupestre pictórico en el sector Pampa El Muerto (extremo norte de Chile). En Actas del xIx Congreso Internacional de Arte Rupestre, pp. 523-536. Mérida: Arkeos.

Guffroy, J. 1999. El arte rupestre del antiguo Perú. Lima: Instituto Francés de Estudios Andinos.

Hostnig, R. 2011. Sumbay: sitio rupestre emblemático del arcaico peruano. $<$ http://www.rupestreweb.info/sumbay. html $>$ [consultado 01-08-2018].

Hostnig, R. 2012. Pinturas rupestres arcaicas de la Provincia de Espinar, Cusco. <http://www.rupestreweb.info/espinar. html $>$ [consultado 01-08-2018].

Hostnig, R. 2013. Camélidos de grandes dimensiones en pinturas arcaicas del centro y centro-sur del Perú. $<$ http:// www.rupestreweb.info/camelidosarcaico.html $>$ [consultado 01-08-2018].

Hyder, W. 2004. Locational analysis in rock-art studies. En The figured landscapes of rock-art: looking at pictures in place, C. Chippindale \& G. Nash, Eds., pp. 85-101. Cambridge: Cambridge University Press.

KLARICH, E. \& Aldenderfer, M. 2001. Qawrankasax Waljawa: arte rupestre de cazadores y pastores en el río Ilave (sur del Perú). Boletín del Museo Chileno de Arte Precolombino 8: 47-58. Santiago.

Meier, V., Guerrero, Z., Cerrillo-Cuenca, E. \& SepúlVEDA, M. 2016. Pinturas rupestres de la precordillera de Arica (norte de Chile). Nuevos avances y síntesis preliminar para la cuenca del río Tignamar. Boletín de la Sociedad de Investigación del Arte Rupestre de Bolivia 30: 36-47. La Paz.

Montt, I. 2002. Faldellines del Período Formativo en el Norte Grande: un ensayo acerca de la historia de su construcción visual. Estudios Atacameños 23: 7-22. San Pedro de Atacama.

Mostny, G. \& Niemeyer, H. 1983. Arte rupestre chileno. Serie El Patrimonio Cultural Chileno. Santiago: Colección Historia del Arte Chileno.

Muñoz, I. \& Briones, L. 1996. Poblados, rutas y arte rupestre precolombinos de Arica: descripción y análisis de sistema de organización. Chungara 28 (1-2): 47-84. Arica.

Muñoz, I. \& Chacama, J. 2006. Complejidad social en las alturas de Arica. Territorio, etnicidad y vinculación con el Estado Inca. Arica: Ediciones Universidad de Tarapacá.

Nielsen, A. 1997. El tráfico caravanero visto desde La Jara. Estudios Atacameños 14: 339-371. San Pedro de Atacama.

Niemeyer, H. 1972. Las pinturas rupestres de la sierra de Arica. Santiago: Jerónimo de Bibar. 
Osorio, D., Sepúlveda, M., Castillo, C. \& Corvalán, M. 2016. Análisis lítico y funcionalidad de sitio de los aleros de la precordillera de Arica (Centro-Sur Andino), durante el Período Arcaico (ca. 10.000-3700 años AP). Intersecciones 17: 77-90. Buenos Aires.

Pettit, P. \& Pike, A. 2007. Dating european palaeolithic cave art: progress, prospects, problems. Journal of Archaeological Method and Theory 14 (1): 27-47. Chicago.

Pimentel, G. 2009. Las huacas del tráfico. Arquitectura ceremonial en rutas prehispánicas del desierto de Atacama. Boletín del Museo Chileno de Arte Precolombino 14 (2): 9-38. Santiago.

Saintenoy, T., Ajata, R., Romero, A. \& Sepúlveda, M. 2017. Panorama regional del poblamiento aldeano prehispánico de la cuenca alta de Azapa en los Altos de Arica: fotointerpretación, geomática y arqueología en los Andes Centro-Sur. Estudios Atacameños 54: 85-110. San Pedro de Atacama.

SAntoro, C. 1992 Ms. Study of rockshelter art in Northern Chile. Final Report, supported by a Grant from National Geographic Society n² 2983/84.

SAntoro, C. \& Dauelsberg, P. 1985. Identificación de indicadores tempo-culturales en el arte rupestre del extremo norte de Chile. En Estudios de arte rupestre. Primeras jornadas de arte y arqueología, C. Aldunate, J. Berenguer \& V. Castro, Eds., pp. 69-86. Santiago: Museo Chileno de Arte Precolombino.

Santoro, C., Osorio, D., Ugalde, P., Sepúlveda, M., Cartajena, I., Standen, V., Gayo, E., Maldonado, A., Rivadeneira, M., Latorre, C., Arriaza, B., Rothhammer, F., De Souza, P., Carrasco, C. \& NúÑez, L. 2016. Cazadores recolectores y pescadores arcaicos del desierto de Atacama. Entre el Pacífico y los Andes. Norte de Chile (ca. 10000-3700 AP). En Prehistoria en Chile: desde sus primeros habitantes hasta los Incas, F. Falabella, M. Uribe, L. Sanhueza, C. Aldunate \& J. Hidalgo, Eds., pp. 117-108. Santiago: Universitaria.

SCHAAFSMA, P. 1985. Form, content and function: theory and method in North American rock art studies. Advances in Archaeological Method and Theory 8: 237-277. Nueva York.

Schiappacasse, F., Castro, V. \& Niemeyer, H. 1989. Los desarrollos regionales en el Norte Grande (1000 a 1400 DC). En culturas de Chile: prehistoria. Desde sus orígenes hasta los albores de la conquista, J. Hidalgo, V. Schiappacasse, H. Niemeyer, C. Aldunate \& I. Solimano, Eds., pp. 181-220. Santiago: Andrés Bello.

Schiappacasse, F. \& Niemeyer, H. 1996. Las pictografías de los aleros de Itiza y de Mullipungo de la sierra de Arica. Chungara 28 (1-2): 253-276. Arica.

Sepúlveda, M. 2008. Pinturas rupestres de la precordillera de Arica (norte de Chile). Re-evaluación a 40 años de la obra pionera de Hans Niemeyer. Boletín de la Sociedad de Investigación del Arte Rupestre de Bolivia 22: 68-79. La Paz.

SepúlvedA, M. 2011a. La tradition naturaliste des peintures rupestres des groupes chasseurs-cueilleurs de l'extrême nord du Chili. En Peuplement et préhistoire en Amérique, D. Vialou, Ed., pp. 453-464. París: Comité des Travaux Historiques et Scientifiques.

Sepúlveda, M. 2011b. Pinturas rupestres y tecnología del color en el extremo sur de Chile. Magallania 39 (1): 193 210. Magallanes.

Sepúlveda, M. 2014. Form in the archaeology of art. En Encyclopedia of Global Archaeology, C. Smith, Ed., pp. 2839-2841. Nueva York: Springer.

Sepúlveda, M., Cornejo, L., Osorio, D., Uribe, M., Llanos, C. \& Castillo, C. 2018. Cazadores-recolectores en tiempos formativos. Trayectoria histórica local en la precordillera del extremo norte de Chile. Chungará 50 (1): 29-50.

Sepúlveda, M., García, M., Calás, E., Carrasco, C. \& SANTORO, C. 2013. Pinturas rupestres y contextos arqueológicos de la precordillera de Arica (extremo norte de Chile). Estudios Atacameños 46: 27-46. San Pedro de Atacama,

Sepúlveda, M. \& Guerrero, Z. 2014. Propuesta de estudio a micro escala de las pinturas rupestres de la precordillera de Arica en el extremo norte de Chile. Ponencia presentada en el Primer Congreso Nacional de Arte Rupestre, Rosario (Argentina).

Sepúlveda, M., Saintenoy, T. \& Faundes, W. 2010. Rock paintings of the precordillera region of northern Chile. Rock Art Research 27 (2): 161-175. Darwin.

Sepúlveda, M., Saintenoy, T., Cornejo, L., Dudognon, C., Espinoza, F., Guerrero, Z. \& Cerrillo-Cuenca, E. 2017. Rock art painting and territoriality in the precordillera of Arica, northern Chile (south central Andes). Archaeological and spatial approaches for the Naturalistic Tradition. Quaternary International. <http://dx.doi.org/10.1016/j. quaint.2017.02.005> [consultado 20-03-2018].

Sieveking, A. 1993. The use of stylistic analysis within the context of West European Upper Paleolithic art. En Rock Art Studies: the post-Stylistic era o Where do we go from Here?, M. Lorblanchet \& P. Bahn, Eds., pp. 27-36. Oxford: Oxbow Monographs.

Sмiтh, B. 2009. Weathering processes and forms. En Geomorphology of Desert Environments, A. Parsons \& A. Abrahams, Eds., pp. 69-100. Springer Netherlands.

Troncoso, A. 2002. Estilo, arte rupestre y sociedad en la zona central de Chile. Complutum 13: 135-153. Madrid.

Troncoso, A., Vergara, F., Pavlovic, D., González, P., Pino, M., Larach, P., Escudero, A., Lamura, N., Moya, F., Pérez, I., Gutiérrez, R., Pascual, D., Belmar, C., Basile, M., López, P., Dávila, C., Vásquez, M. \& Urzúa, P. 2016. Dinámica espacial y temporal de las ocupaciones prehispánicas en la cuenca hidrográfica del río Limarí $\left(30^{\circ}\right.$ Lat. S). Chungara 48 (2): 199-224. Arica.

UlLOA, L. 1985. Vestimentas y adornos prehispánicos en Arica. En Arica diez mil años, L. Ulloa, Ed., pp. 21-44. Santiago: Museo Chileno de Arte Precolombino.

Valenzuela, D., 2007. Arte, tecnología y estilo: Propuesta teórico-metodológica para el estudio de la producción en 
grabados rupestres. Tesis para optar al grado de Magíster en Antropología, Universidad Tarapacá-Universidad Católica del Norte, Arica-San Pedro de Atacama.

Valenzuela, D. 2013. Grabados rupestres y tecnología: un acercamiento a sus dimensiones sociales, valle de Lluta, norte de Chile. Tesis para optar al grado de Doctora, Departamento de Antropología, Universidad TarapacáInstituto de Investigación Arqueológica, Universidad Católica del Norte, Arica-San Pedro de Atacama.

Valenzuela, D., Sepúlveda, M., Santoro, C. \& Montt, I. 2014. Arte rupestre, estilo y cronología: la necesidad de un contexto histórico para las manifestaciones rupestres en costa y valles del extremo norte de Chile. Interciencia 39 (7): 444-449. Caracas.

Vergara, F. 2013. El lado material de la estética en el arte rupestre. Boletín del Museo Chileno de Arte Precolombino 18 (2): 33-47. Santiago.
Vilches, F. \& CABello, G. 2011. Variaciones sobre un mismo tema: El arte rupestre asociado al complejo Pica-Tarapacá, norte de Chile. Chungara 43 (1): 37-52. Arica.

Villagrán, C., Castro, V., Sánchez, G., Romo, M., Latorre, C. \& HinojosA, L. 1998. La tradición surandina del desierto: etnobotánica del área del Salar de Atacama (provincia de El Loa, Región de Antofagasta). Estudios Atacameños 16: 7-106. San Pedro de Atacama.

Villagrán, C., Castro, V., Sánchez, G., Hinojosa, L. \& LATORRe, C. 1999. La tradición altiplánica: estudio etnobotánico en los Andes de Iquique, I Región, Chile. Chungara 31 (1): 81-186. Arica.

Villagrán, C., KALÍN, M. \& ARMESTo, J. 1982. La vegetación de un transecto altitudinal en los Andes del norte de Chile (18-191S). En El ambiente natural y las poblaciones humanas de los Andes del norte de Chile, A. Veloso \& E. Bustos, Eds., pp. 13-69. Montevideo: Rostlac. 